\title{
Identifying the Institutional Decision Process to Introduce Decentralized Sanitation in the City of Kunming (China)
}

\author{
Edi Medilanski · Liang Chuan · Hans-Joachim Mosler • \\ Roland Schertenleib - Tove A. Larsen
}

Received: 10 October 2005/ Accepted: 16 July 2006

(C) Springer Science+Business Media, LLC 2007

\begin{abstract}
We conducted a study of the institutional barriers to introducing urine source separation in the urban area of Kunming, China. On the basis of a stakeholder analysis, we constructed stakeholder diagrams showing the relative importance of decisionmaking power and (positive) interest in the topic. A hypothetical decision-making process for the urban case was derived based on a successful pilot project in a periurban area. All our results were evaluated by the stakeholders. We concluded that although a number of primary stakeholders have a large interest in testing
\end{abstract}

\section{E. Medilanski}

High Performance Organisations AG,

Management Consulting, Kantonsstrasse 14,

8807 Freienbach, Switzerland

e mail: edikasuku@yahoo.fr

\section{Chuan}

Sustainable Development Research,

Yunnan Academy of Social Sciences, Huanchengxilu 577, 650034 Kunming, Yunnan Province, People's Republic of China

\section{H. J. Mosler}

Systems Analysis, Integrated Assessment and Modelling (Siam),

Swiss Federal Institute of Aquatic Science and Technology, Eawag, 8600 Dubendorf, Switzerland

\section{R. Schertenleib}

Water and Sanitation in Developing Countries (Sandec), Swiss Federal Institute of Aquatic Science and Technology, Eawag, 8600 Dubendorf, Switzerland

T. A. Larsen $(\bowtie)$

Swiss Federal Institute of Aquatic Science and Technology, Eawag, 8600 Dubendorf, Switzerland

e mail: larsen@eawag.ch urine source separation also in an urban context, most of the key stakeholders would be reluctant to this idea. However, the success in the periurban area showed that even a single, well-received pilot project can trigger the process of broad dissemination of new technologies. Whereas the institutional setting for such a pilot project is favorable in Kunming, a major challenge will be to adapt the technology to the demands of an urban population. Methodologically, we developed an approach to corroborate a stakeholder analysis with the perception of the stakeholders themselves. This is important not only in order to validate the analysis but also to bridge the theoretical gap between stakeholder analysis and stakeholder involvement. We also show that in disagreement with the assumption of most policy theories, local stakeholders consider informal decision pathways to be of great importance in actual policy-making.

Keywords Decision process - Ecological sanitation Dianchi Lake · Institutional analysis - Stakeholders . Urine separation · Wastewater

\section{Introduction}

The prevailing wastewater management system in Europe and the United States is based on an extended sewer system and centralized wastewater treatment. In most of these countries, this system has proven very successful for controlling excreta-related health problems as well as water pollution and is, consequently, seen as the key to solving wastewater problems in other parts of the world. However, centralized sewer-based 
Fig. 1 The city of Kunming lies on the northern shore of Dianchi Lake. Caohai is the northern section of Dianchi Lake closest to the city of Kunming. It is separated from the southern section (Waihai) by a dam and represents less than $1 \%$ of the total lake

volume and $2.5 \%$ of its total surface.

(Map drawn after a figure from World Bank 1996)

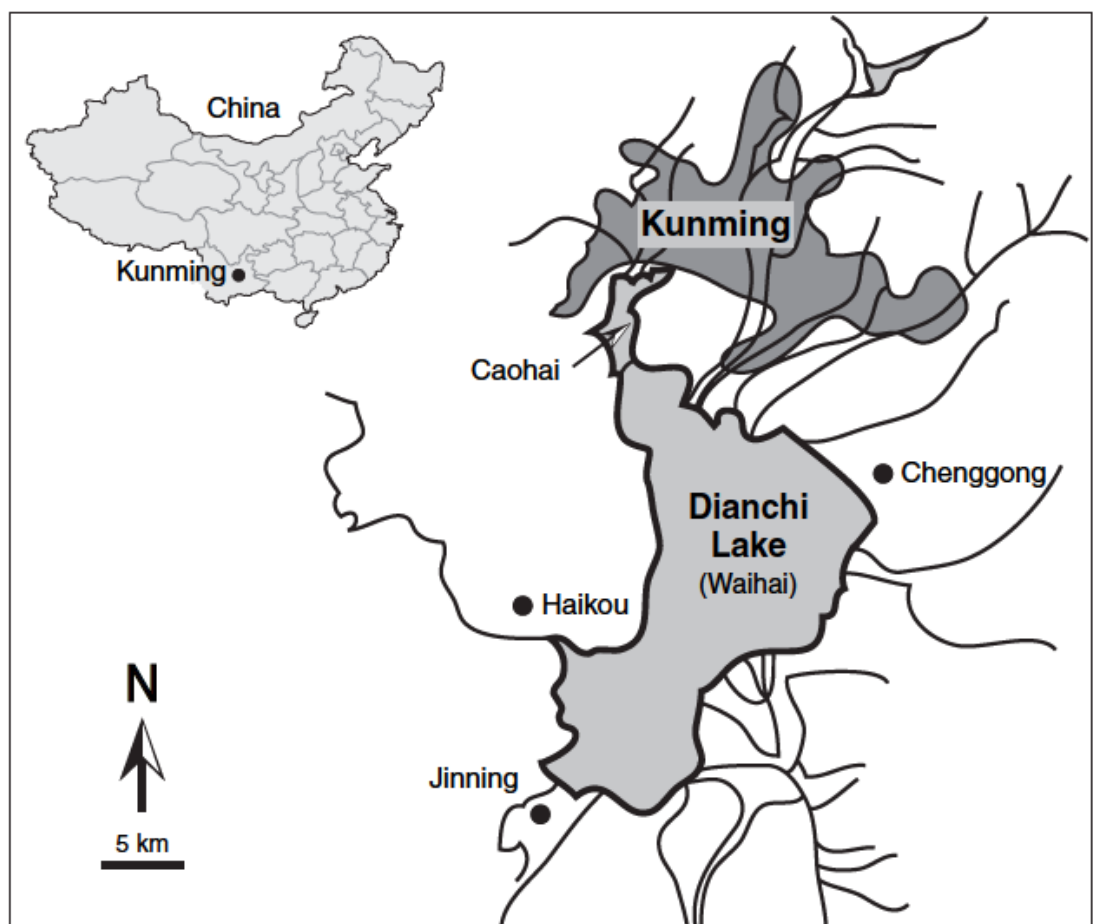

systems have disadvantages also (see, e.g., Larsen and Gujer 2001, for an overview), a fact that is often neglected. Such a system is not well suited for fastgrowing cities, especially in water-scarce countries. It depends not only on the existence of a complete sewer system but also on a system to supply sufficient flushing water-in both cases, a huge economic and institutional challenge for a fast-growing city. The financial resources targeted for the construction of sewer lines normally account for about $80 \%$ of the total investment in centralized wastewater systems. This often leads to all of the funding being used for sewers, leaving nothing or little for water pollution control measures. For instance, in Latin America, where a relatively large proportion of the population is connected to a sewer system, only an estimated $10 \%$ of the collected sewage is treated at all, and the quality of treatment is generally low (UNEP 2002). Moreover, high population densities might rapidly bring such cities to the limit of available water resources, even in regions with rainfall comparable to European conditions. Water resources are limited not only in terms of available drinking and flushing water but also in terms of available natural water resources to dilute the treated wastewater.

However, in many fast-growing cities with limited water resources, there is a huge demand for adequate solutions to the increasing problems of water pollution control. In such and similar situations, there is a growing tendency to argue that decentralized solutions would be both more effective and more cost- efficient than a sewer-based centralized system. Important results of this increasing acknowledgment of decentralized wastewater management are the formulation of the Bellagio Principles for Sustainable Sanitation and the development of the HouseholdCentered Environmental Sanitation (HCES) approach by the Environmental Sanitation Working Group (ESWG), a specialist working group of the United Nations Water Supply and Sanitation Collaborative Council (WSSCC) (Schertenleib and others 2003). The HCES approach emphasizes solutions close to the household or neighborhood level and a resourcebased thinking as opposed to the linear thinking of centralized wastewater treatment.

In this article, we examine the situation in urban areas in Southeast Asia, exemplified by the city of Kunming, the capital of the Chinese province Yunnan in the catchment area of Dianchi Lake, one of the most polluted lakes in China (Figure 1). Dianchi Lake is heavily eutrophied due to phosphorus, stemming to a large extent from the wastewater of Kunming (World Bank 1996a). The metropolitan area of Kunming is rapidly growing (from 2.6 million today to 4.5 million in 20 years; KUPDI 2003), and even with huge investments in treatment plants (about US\$ $300 \mathrm{mil}-$ lions; Chen 2000), only about $25 \%$ of the wastewater produced today is treated (Huang and others, in press). A main reason for this is the large amount of clear water infiltrating into the sewer system. To our knowledge, however, the very expensive renovation 
Fig. 2 Examples of urine separating toilets functioning without and with water. A

The urine separating dry toilets (courtesy of Lin Jiang, Guangxi Province, China). B Urine separating flushing toilet, so called NoMix toilet (from Roediger, Germany)
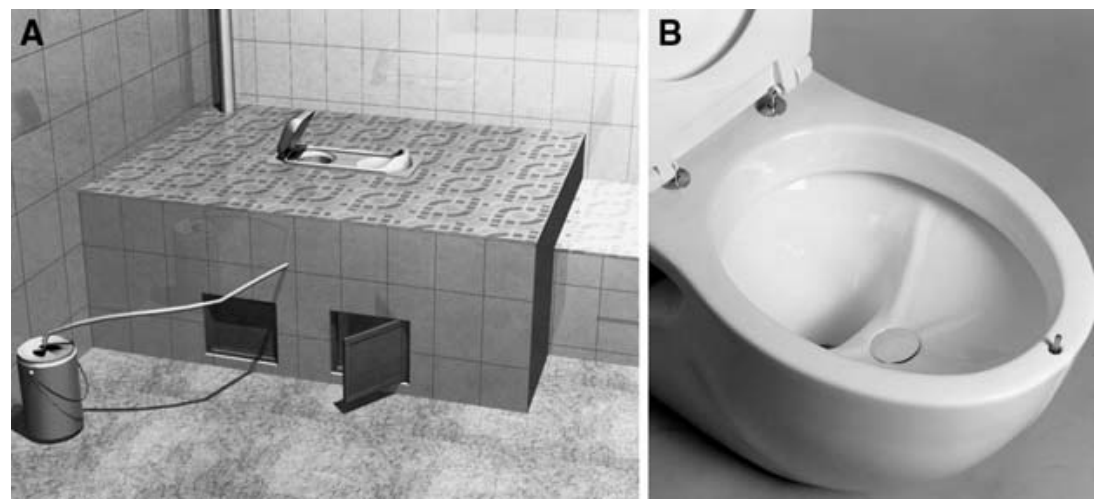

of the sewer system, which is partially based on open channels, has never been seriously considered. Furthermore, the low depth and the restricted amount of water in Dianchi Lake leads to a situation where even perfect sewerage with state-of-the-art wastewater treatment would be inadequate to reach the high goals of the local and national authorities with respect to the water quality of the lake (Huang and others, in press).

In Kunming, there is a high degree of consensus among the stakeholders that measures at the source will be necessary in order to solve the problems of Dianchi Lake, and toilet waste contributing most of the phosphorus to domestic wastewater is considered an important target for such measures (Medilanski and others 2006). In the part of the project discussed in this article, we aimed to understand the institutional decision process and the potential barriers to introduce such decentralized alternatives in the city of Kunming.

We concentrated on toilets, choosing a urine-separating dry toilet (Figure 2A) for the periurban and a flushing urine-separating toilet (NoMix toilet, Figure 2B) for the urban situation. The urine-separating dry toilet is already foreseen in the Five Year Plan for rural and periurban areas around Dianchi Lake (Task Group 2001). For the urban areas, we chose the NoMix technology instead of dry toilets because it exists in a form that is more acceptable for an urban population (Lienert and Larsen 2006). Although dry toilets coping with the entire toilet waste are more effective from the point of view of phosphorus containment, problems of acceptance might dominate any discussion on institutional aspects of introducing such technology. Yet, the NoMix toilet can be relatively effective in reducing the phosphorus emissions from cities (see, e.g., Larsen and others 2001) and the institutional process is not really dependent on the specific technology chosen.

As a first step, we conducted a stakeholder analysis and then we analyzed a comparable institutional decision process in a periurban village from which we derived the possible process in the urban environment.
The stakeholder analysis and the derived decision process were then evaluated by the stakeholders in order to ensure that we had understood the institutional situation properly.

\section{Methodology and Procedures}

Commonly, learning about institutions is expressed as "learning about the rules of the game in society." North (1990) differentiated between formal (i.e., laws and contracts) and informal (i.e., conventions or codes of behavior) rules, which together build an institutional framework on which organizations develop. In our institutional analysis, we adopted the World Bank definition: "An institutional analysis is an analytical approach that uses qualitative methods to unpack the 'black box' of decision making and implementation processes" (World Bank 2003). We concentrate on the formal rules and the governmental organization as the most central institutional components in the implementation of urine source separation in the city of Kunming. In a first step, we attempt to understand the relevant Chinese legal framework, the governmental organization, the stakeholders, and the real decisionmaking process that took place when a pilot project with urine-separating dry toilets was implemented in a village. Based on this knowledge, we extrapolate the results to identify a hypothetical decision-making process to introduce urine source separation in the city of Kunming. Finally, our results were assessed in a workshop by representatives from a number of the involved stakeholders.

\section{Legal Framework and Governmental Organization}

We gained a general overview of the legal framework and governmental organization related to environmental issues through a literature survey and contacts to Chinese experts in urine source separation and other 
ecological sanitation methodologies. Many of these experts are internationally renowned specialists and located in Beijing (Tsinghua University, Chinese Academy of Science, Chinese Academy of Agricultural Engineering), Chengdu (China Biogas Society), and Nanning (Guangxi Government). Moreover, we profited from the local knowledge of our partners from two local governmental institutes in Kunming (see section Case Study).

Case Study: Implementation of Urine Source Separation in a Village

In order to gain first practical experience with the decision process involved in the introduction of urine source separation in China, a small pilot project was conducted in a periurban village (Zhonghe village) 30 $\mathrm{km}$ southeast of Kunming, near the town of Chenggong. The pilot project was initiated and financed by the Swiss NCCR North South Programme and run by our Chinese partners from the Kunming Institute of Environmental Science (KIES) and Yunnan Academy of Social Sciences (YASS). In this project, more than 100 urine-separating dry toilets were installed under the guidance of KIES and population surveys were conducted by YASS. The purpose of these surveys was to identify people's requirements for sanitation and fertilizers and the factors of success in the pilot project. Based on these findings, the Yunnan Academy of Social Sciences will make recommendations for policymakers for further dissemination of this sanitation system.

\section{Stakeholder Analysis}

Our choice of stakeholders was guided by the final goal of introducing an urbanized version of urine source separation. The stakeholder analysis followed the guideline of the British Overseas Development Administration (Department for International Development 1995b), slightly adapted to our research purpose. It comprises three consecutive parts:

1. Preparation of a stakeholder characterization table that lists the following:

- all potential stakeholders

- their priorities in relation to the concept being addressed (in this case, the introduction of urine source separation in the city)

- the impact on these general priorities (positive, negative, or neutral) of introducing urine source separation in the city
2. Quantification of the decision-making power of each stakeholder and their interest in the concept of introducing urine source separation in an urban context. The chosen scale spans from 0 (decision power or interest minimal) to 5 (maximal). The two values attributed to each stakeholder are used to position them relatively to each other in a stakeholder diagram showing interest versus decision-making power.

3. Based on the stakeholder diagram produced in item 2, the relative importance of the stakeholders is visualized (Figure 6). We use our estimation of decision-making power ( $\mathrm{dmp}$ ) and interest (i) values to constitute three classes of stakeholders: key stakeholders, who are the most important decision-makers (dmp $\geq 4)$; secondary stakeholders having low interest and decision power $(\mathrm{dmp}+\mathrm{i}<4)$; and primary stakeholders, who are between those two classes $(\mathrm{dmp}+\mathrm{i} \geq 4$ with dmp < 4). Using this diagram, we draw conclusions concerning the risks and potentials affecting the implementation of urban urine source separation.

The stakeholder identification and characterization are based on the following steps: the literature survey, the contacts with Chinese experts on ecological sanitation technologies, and the case study. Furthermore, for most of the stakeholders, the characterization was completed after personal interviews with specific questions regarding their role and interest in the concept of urban urine separation (Medilanski and others 2006). During these interviews, the stakeholders described themselves and their relations with other stakeholders.

Extrapolation of the Case Study Results to an Urban Environment

Based on the stakeholder analysis and the case study, we developed the hypothetical decision-making process for implementing a urine-separating flushing toilet (NoMix toilet) in the city of Kunming. We chose the NoMix toilet as the example because we assumed that it would be more easily accepted by an urban population than the dry toilet. The extrapolation was made in cooperation with our Chinese partners responsible for the case study.

Workshop: Assessment by Stakeholders and Adjustment of the Results

The results were presented in a workshop in Kunming, organized in cooperation with our Chinese partners. 
During the workshop, representatives from ten of the identified stakeholders assessed our main research results. The stakeholder diagram and the hypothetical decision process for introducing urine source separation in the city of Kunming were presented on two posters and evaluated by the participants. In the evaluation, a representative from each stakeholder filled in a form to evaluate the degree of agreement with the information on the poster (scale from 1, "I do not agree at all," to 5, "I fully agree"). The stakeholder diagram as well as the decision process was modified in a group process in order to increase the consensus on the results.

\section{Results}

\section{Legal Framework}

Due to an increasing pressure on natural resources following the population growth and the rapid economic development in China, a series of principles, laws, and measures for environmental protection was enacted and implemented during the 1980s. The Environmental Protection Law of the People's Republic of China from 1989 contains the main ruling for environmental protection in China, complemented with a number of more specific laws (Chinagate 2004; also see this website for the English version of other laws referred to in this subsection).

We found little legislative support for practical trials and implementation of innovative urban wastewater management alternatives. Basically, the Law on Prevention and Control of Water Pollution (Art. 19) specifies that urban sewage should be treated centrally, and decentralized collection and treatment of human excreta is not favored. Nevertheless, there is some flexibility in the legislative system to allow for pilot projects in this new technical field-especially within the framework of a Five Year Plan-and the government might even reward innovative projects and achievements that bring improvements to environmental protection (Environmental Protection Law, Art. 8; Water Law, Art. 8).

\section{Governmental Organization}

The Chinese government is present on five to six levels of administration: state, province, municipality, and two to three further local levels (Mi 2001).

From the state to the local administrative levels, there are three lines in the chain of command: the Congress, the government, and the Communist Party; their com- petencies are defined in the Chinese Constitution (1982). The Congress holds the legislative power (Art. 99), the government holds the executive power (Art. 86), and the Communist Party gives the ideological guideline for the governmental actions (Preamble).

At the national level, the specific competencies of the government are split into ministries that are coordinated by the State Council. Ministries are represented at the lower levels of administration by a department, a bureau, a station, or a committee. Figure 3 illustrates the specific case of the environmental protection organization in the government and shows the distribution of offices and lines of communication between them and through the different levels of administration. There is no Ministry of Environment at the national level because the enforcement of environmental protection is considered a transministerial issue.

The unitary political system of China (as opposed to the federal system of, e.g., the United States and Switzerland) is very hierarchically organized. The decision-making power is divided among party officials, legislative bodies, and administrative units at each level. The case of the Dianchi Lake Protection Bureau shows that the Chinese government will intervene also at lower levels if it deems this necessary. This corresponds to the normal policy in Europe of coordinating decisions at the catchment level of larger aquatic systems (e.g., the North Sea, or large rivers like the Rhine) - a policy that makes perfect sense from the point of view of the environment.

\section{Case Study}

As a starting point for understanding the possible decision-making process in an urban area, we looked at the implementation of more than 100 urine-separating dry toilets in Zhonghe village near Kunming, conducted by KIES (Figure 4).

A previous implementation of 124 units north of the town of Jinning (Taishi village) on the southeast side of the lake took place in 2002 and was also conducted by KIES. In this first project, the dry toilet system was poorly accepted by the villagers, so we initiated a second pilot project. In the Zhonghe village project, collaboration with dry toilet specialists in Guangxi Province and local social scientists (from YASS) was encouraged in order to increase the chances of success and further dissemination of the sanitation system. The project was highly successful and led to a decision on the future dissemination of 100,000 dry toilets around Kunming by the end of 2007 (NCCR North South 2005). In this article, however, we discuss only the decision-making process of implementation. 
Fig. 3 Lines of communication among the main environmental protection bodies in the government. Solid lines illustrate primary management communications; dotted lines illustrate secondary management communications

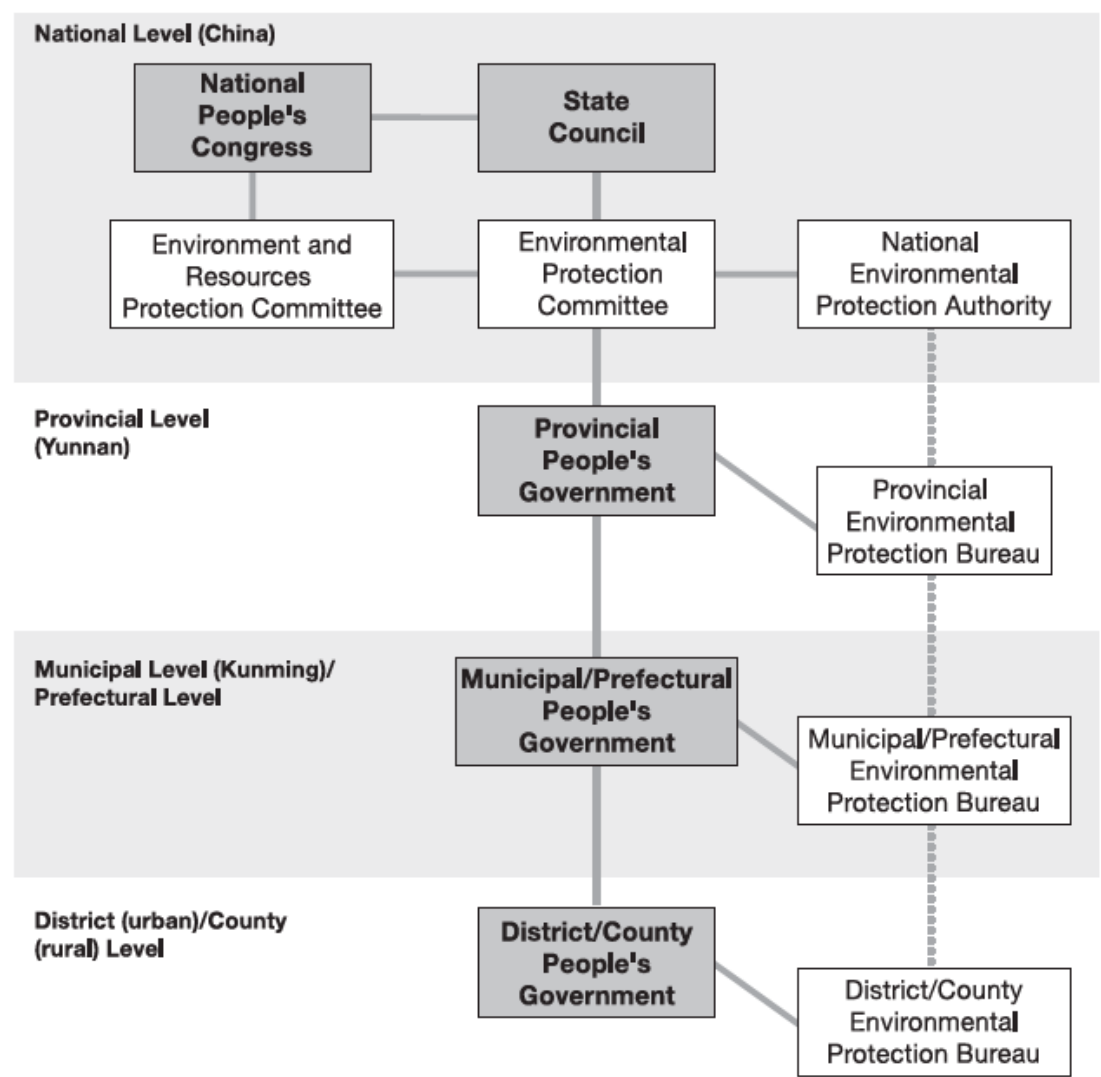

The institution responsible for the pilot project, KIES, is positioned under the Municipal Environmental Protection Bureau (MEPB) (Figure 4), which allocates funds, controls the employees, and gives guidelines for the activity of the research institute. KIES is also partly financed by the City Institute of Science and Technology, but those funds are more closely allocated to specific projects.

When KIES learned in 2002 via the Internet about the successful implementation of urine-separating dry toilets in the neighboring Guangxi Province, a KIES representative visited the project leaders in Nanning (capital of Guangxi). Convinced of the advantages of the system, he submitted a proposal to the MEPB to disseminate the system in rural and periurban areas of the Dianchi Basin (Figure 4). MEPB supported the proposal and forwarded it to the municipal government. The government endorsed the proposal and integrated this project in the 10th Five Year Plan that was released in December 2001 (Task Group 2001). The dissemination of dry toilets then became an official policy giving governmental support to KIES, which then followed two possible paths to proceed with the implementation. In the first implementation project, KIES used the official way (Figure 4-1), contacting first the county Environmental Protection Bureau (EPB). EPB introduced KIES to the township govern- ment and to the local administrative village committee responsible for Taishi village. With the support of the village committee, KIES contracted local workers to build the dry toilet units in the village. In the second project, the implementation steps were slightly different from this strictly official pathway. Because the local county EPB responsible for Zhonghe village showed a limited interest in participating, the following informal procedure based on former contacts was adopted (Figure 4-2): The committee responsible for Zhonghe village was directly contacted and the MEBP was informed. This direct way of communication saved KIES both time and financial resources.

\section{The Stakeholder Analysis}

Figure 5 lists the identified stakeholders and summarizes their general priorities and estimated impact (positive, negative, or neutral) of the concept of urban urine source separation on those priorities.

Most of the stakeholders that we believe to play a role in the implementation and management of urine source separation in the city of Kunming are governmental offices and we identified the Dianchi Lake Protection Bureau (\#4, Figure 5) as the most important of these offices. The Dianchi Lake Protection Bureau is located at the municipal level of administration and 
Fig. 4 Decision making processes for the implementation of urine separating dry toilets. The arrows (1) denote the strictly official pathway to get to the administrative village. In our implementation project, the village could be directly

reached (2). See the text for a detailed description of the decision making process

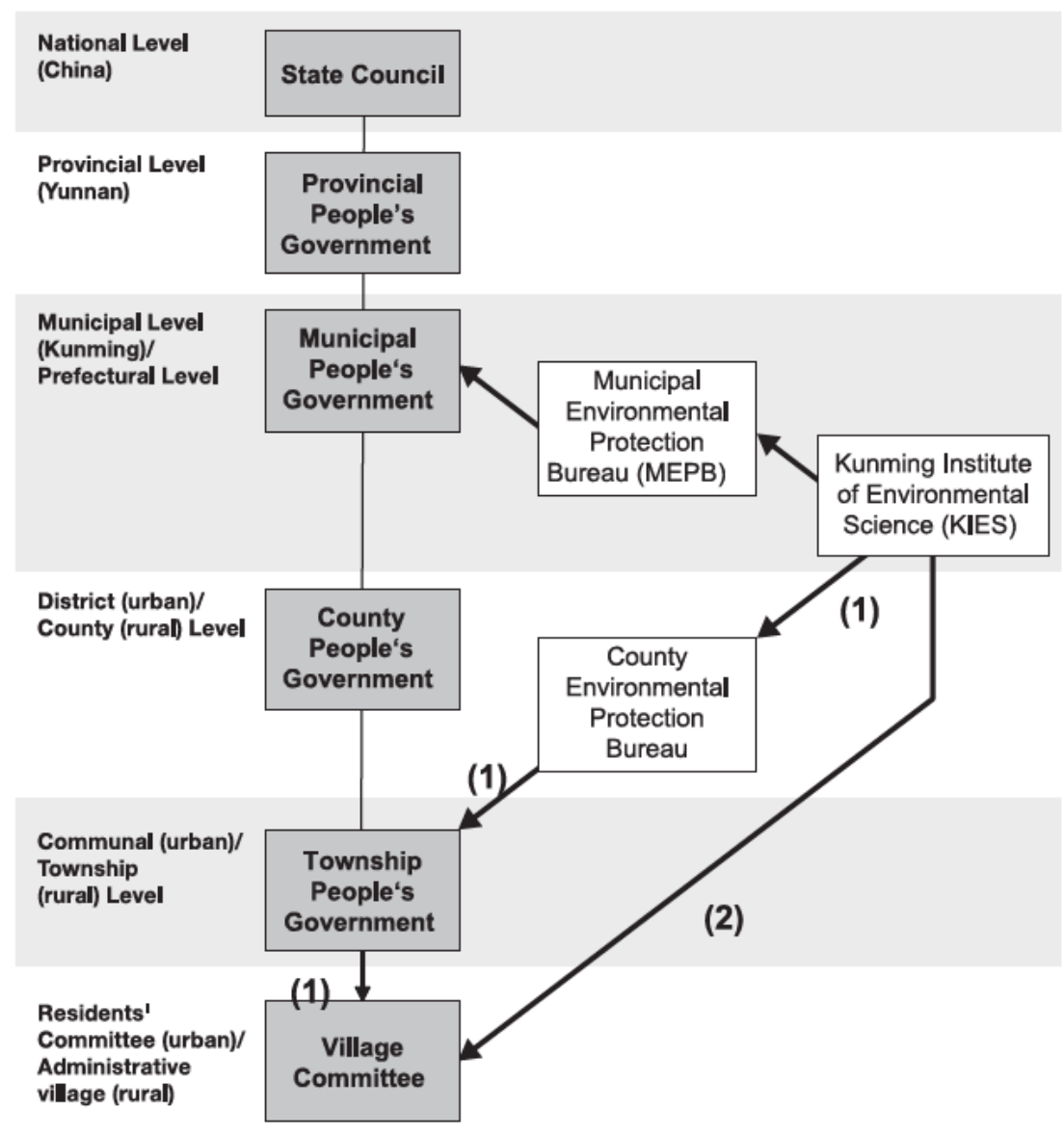

represents the central coordinator and highest body of experts for all issues related to wastewater management and the protection of Dianchi Lake. With increasing urgency of the problems connected to the lake pollution and shortage of water supply for the city, the Dianchi Lake Protection Bureau was given extensive management competencies. Since 2002, the Kunming Sewer Corporation (\#8) responsible for the wastewater management of the city has been placed under the authority of the Dianchi Lake Protection Bureau in order to reinforce the latter's global decision power on this matter. Environment-related monitoring and research services have, however, remained the competency of the Municipal Environmental Protection Bureau (\#11).

Leaders from villages where urine-separating dry toilets are implemented were also included in the stakeholder list (\#30 and \#31). Zhonghe village is under the local responsibility of the Dayu Government (\#26) and the Chenggong Environmental Protection Bureau (\#27), both at the county level of administration.

Nongovernmental stakeholders included real estate companies (\#7), which are private organizations in today's China, the Department of Environmental
Sciences at Kunming University of Science and Technology (\#33), and a large phosphorus mining company (\#32) still in activity near Dianchi Lake and contributing to its pollution (World Bank 1996a).

Several stakeholders outside of Kunming were also considered. Research institutes in the field of ecological sanitation located in Beijing (\#13, \#14, and \#15) were included because of their expertise. The Tianjin Environmental Protection Bureau (\#34) is an office that is currently investigating alternatives to the planned implementation of 15 wastewater treatment plants in townships around Tianjin and has in this connection evaluated the possibility of urine-separating technologies. Finally, a Swiss project rehabilitating a historic village in the Shaxi Valley (Yunnan Province) (\#35) could also contribute with its experience because the introduction of urine-separating dry toilets is part of their agenda (Feiner 2004).

In Figure 5 we summarize the estimated impact of the introduction of urine source separation in cities on the stakeholders' general priorities. From the list, it is seen that for many of the stakeholders, we expect urine source separation to have a positive influence on one or more of their priorities. As a consequence, we 


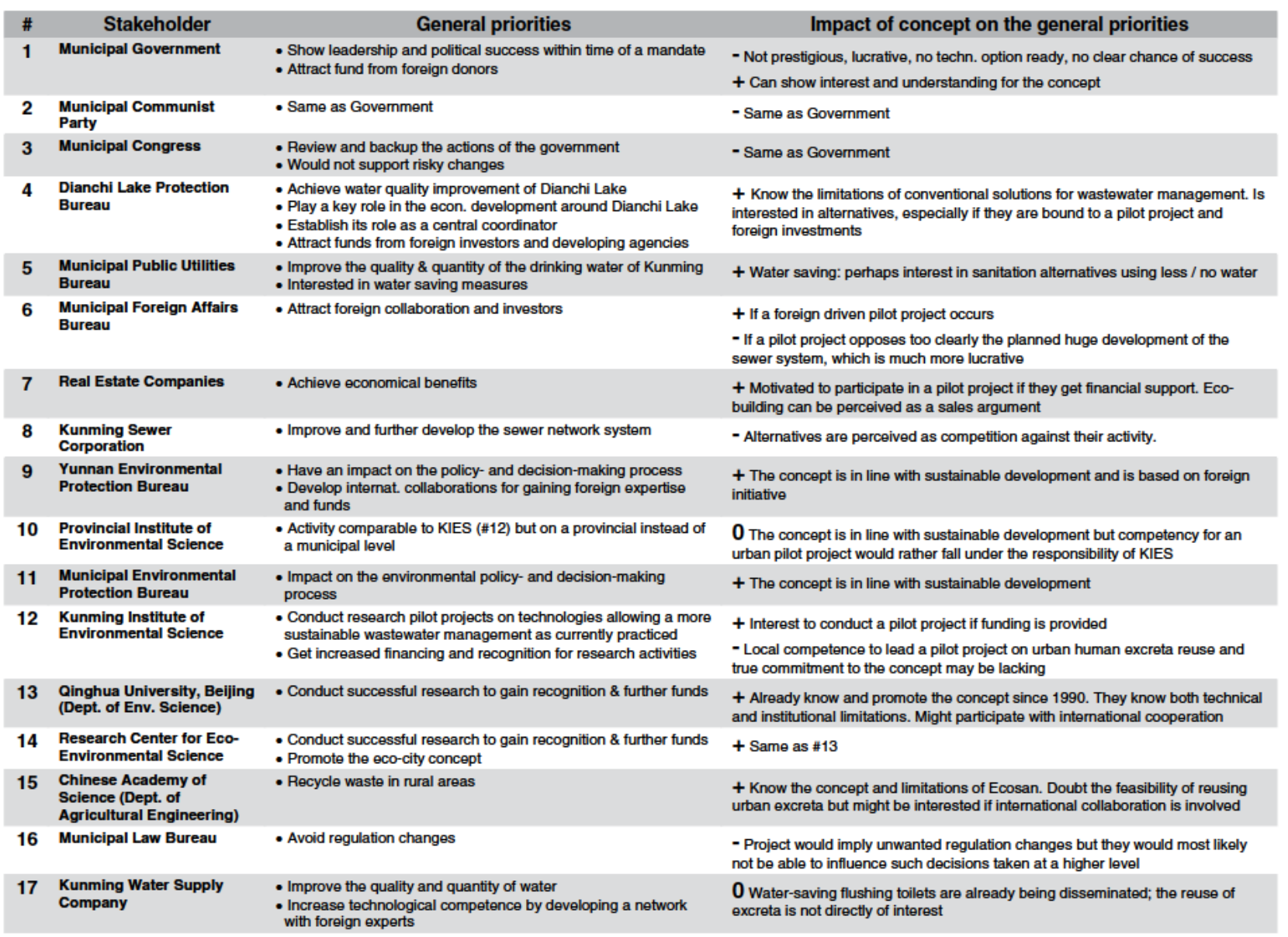

Fig. 5 General priorities of stakeholders and the impacts of introducing urine source separation on these priorities

assume that more than half of the stakeholders have at least a partial positive attitude toward urban urine source separation and reuse. We expect ten stakeholders to have a neutral position mainly because they are not directly concerned, and we expect only eight stakeholders to be negative toward the concept. However, the most important governmental bodies in Kunming - the Municipal Government, Party, and Congress (\#1, \#2 and \#3, respectively)—are found in this third group.

Based on the information gathered for the stakeholder characterization, we estimated values for their decision-making power and interest to introduce urine source separation in the city. These results are presented in a stakeholder diagram in which three groups of stakeholders (key, primary, and secondary) are distinguished (Figure 6).

The Municipal Government, Party, and Congress are the final decision-makers and, therefore, key stakeholders. They will most likely not commit themselves to implement urine source separation in the city unless the chance of success is clear. The support of the
Dianchi Lake Protection Bureau (\#4) is also crucial because of its prominent status as the most important group of experts and managers in all issues related to wastewater management and Dianchi Lake protection.

The primary stakeholder group includes the main experts in ecological sanitation and environmental protection. Among these primary stakeholders, several research institutes seem particularly supportive of the concept of urban urine source separation (interest $=4$ ). In particular, the famous research institutes of Beijing have extensive experience with issues related to ecological sanitation and are familiar with the limitations for urban applications. Secondary stakeholders are active mostly on the administrative level and would not be very involved in the decision-making process to implement urine source separation in the city.

Extrapolation of the Case Study Results to an Urban Environment

Based on the practical experience in the case study, we developed, together with our Chinese partners, 


\begin{tabular}{|c|c|c|c|}
\hline 18 & $\begin{array}{l}\text { Yunnan Academy of Social } \\
\text { Science }\end{array}$ & $\begin{array}{l}\text { - Develop international collaboration on the topic of sustainable } \\
\text { development to gain funds and recognition } \\
\text { - Influence policy making }\end{array}$ & + International collaboration and topic fully in line with interests \\
\hline 19 & $\begin{array}{l}\text { Provincial Soil and } \\
\text { Fertilizer Station }\end{array}$ & $\begin{array}{l}\text { - Develop a market for organic fertilizer produced from human } \\
\text { and animal excreta } \\
\text { - Involve the private sector for having a more dynamic activity } \\
\text { and, according to them, less corruption }\end{array}$ & $\begin{array}{l}\text { + Already produces solid fertilizer from solid excreta } \\
\text { O Not using human urine at the moment }\end{array}$ \\
\hline 20 & $\begin{array}{l}\text { Environmental Monitoring } \\
\text { Station of the Yunnan EPB }\end{array}$ & - A service administrative office with no particular ambitions & $\mathbf{O}$ Not directly concerned \\
\hline 21 & $\begin{array}{l}\text { Municipal Public Health } \\
\text { Bureau }\end{array}$ & - Underline health aspects in different projects & + Improved hygiene is an advantage of the urine-diverting dry toilet system \\
\hline 23 & $\begin{array}{l}\text { Municipal Agriculture } \\
\text { Bureau }\end{array}$ & - Disseminate biogas tanks and fertilizer production in rural areas & $\begin{array}{l}0 \text { The reuse of human excreta is interesting in rural areas in combination of the } \\
\text { implementation of biogas tanks; biogas tanks use is very limited in urban areas }\end{array}$ \\
\hline 24 & $\begin{array}{l}\text { Municipal Urban Planning } \\
\text { Administration Bureau }\end{array}$ & $\begin{array}{l}\text { - Especially work on the development of road network and urban } \\
\text { traffic }\end{array}$ & $\mathbf{O}$ Not directly related \\
\hline 25 & Municipal Financial Bureau & - Manage the funds, if possible also from foreign donors. & $\begin{array}{l}\text { Their own participation in the funding of an urban pilot project might be } \\
\text { facilitated if foreign funds are also invested }\end{array}$ \\
\hline 26 & $\begin{array}{l}\text { Dayu Township } \\
\text { Government }\end{array}$ & $\begin{array}{l}\text { - Implement decisions from higher level (low level of } \\
\text { administration) }\end{array}$ & + A pilot project in their county might give them some prestige \\
\hline 27 & $\begin{array}{l}\text { Chenggong Environmental } \\
\text { Protection Bureau }\end{array}$ & $\begin{array}{l}\text { - Promote environmental projects at the local level } \\
\text { - Gain more recognition for their work }\end{array}$ & $\begin{array}{l}\text { + A pilot project in their county will give more recognition to their work in the } \\
\text { environmental field }\end{array}$ \\
\hline 28 & $\begin{array}{l}\text { Taishi Township } \\
\text { Government }\end{array}$ & - No particular ambitions (low level of administration) & O Will not take many decisions; is responsible for implementation at local level \\
\hline 29 & County Fertilizer Station & $\begin{array}{l}\text { - Promote the shift from chemical to organic fertilizer at a local } \\
\text { level }\end{array}$ & + The concept to increase the reuse of human excreta in line with their interests \\
\hline 30 & $\begin{array}{l}\text { Zhonghe Village (second } \\
\text { implementation project) }\end{array}$ & $\begin{array}{l}\text { - Leaders want to attract interest and investors to modernize their } \\
\text { village } \\
\text { - Leaders want to profile themselves as successful }\end{array}$ & $\begin{array}{l}\text { + Rural areas are getting modernized; would be interested in modern } \\
\text { applications in his village }\end{array}$ \\
\hline 31 & $\begin{array}{l}\text { Taishi Village (first } \\
\text { implementation project) }\end{array}$ & $\begin{array}{l}\text { - Leaders want to attract interest and investors to modemize } \\
\text { village } \\
\text { - Laders want to profile themselves as successful }\end{array}$ & $\begin{array}{l}0 \text { Promises of improvements of their sanitation were not all fulfilled. They will not } \\
\text { expect much from a future project }\end{array}$ \\
\hline 32 & $\begin{array}{l}\text { Phosphorus Mining } \\
\text { Company }\end{array}$ & $\begin{array}{l}\text { - No special ambition, just to continue the current activity as } \\
\text { usual }\end{array}$ & O At this stage a pilot project would be too small to influence their work \\
\hline 33 & $\begin{array}{l}\text { Kunming University of } \\
\text { Science and Technology } \\
\text { (Dept. of Env. Science) }\end{array}$ & $\begin{array}{l}\text { - To conduct successful research for gaining recognition and } \\
\text { funding }\end{array}$ & + Will get increased competence and recognition for international collaboration \\
\hline 34 & $\begin{array}{l}\text { Tianjin Environmental } \\
\text { Protection Bureau }\end{array}$ & $\begin{array}{l}\text { - To get expertise and funding to find alternatives for the planned } \\
\text { development of conv. sewer system in townships around Tianjin }\end{array}$ & $\begin{array}{l}\text { O Interested in solutions, less interested in research involved; for them it is } \\
\text { urgent to suggest alternatives to a plan already decided by the government }\end{array}$ \\
\hline
\end{tabular}

Fig. 5 Continued

the hypothetical decision-making process to implement urine-separating flushing toilets in an urban environment. Figure 7 shows the proposed decision-making process with the following successive decision steps:

1. The implementation of urine-separating toilets will be first submitted as a detailed common proposition from the MEPB and the Dianchi Lake Protection Bureau (DLPB) to the Municipal Government. The communication between these two governmental offices will be established from the beginning. The reason is that a decision of disseminating such an innovative sanitation alternative can be taken only on the basis of one or several successful pilot projects. DLPB is responsible for the wastewater infrastructure and management, but the research in this field is within the competency of the MEPB. Therefore, it is the MEPB that conducts pilot projects, but DLPB must be informed of and approve the concept before such a project is submitted to the government. The Municipal Government will examine the proposition and might ask the concerned governmental bodies for complementary information before submitting the final proposal to the Municipal Congress for approval.

2. After support from both the Congress and the Government, the implementation of the pilot project(s) can start. Because the setting is now urban, not periurban, the MEPB will carry the responsibility but delegate the actual implementation to its research institute, KIES, which is already responsible for pilot projects implementing urineseparating dry toilets in periurban areas.

3. The Kunming Institute of Environmental Science will contract, finance, and supervise local private companies for the implementation work of a pilot project in Kunming.

4. If the implementation occurs in urban areas outside of Kunming (smaller towns, new developing urban areas), KIES will contract the companies only after contacting the local government office to involve them in the local management of the project. Because the urban project is led by MEPB, the support of the corresponding local EPBs is automatic. 

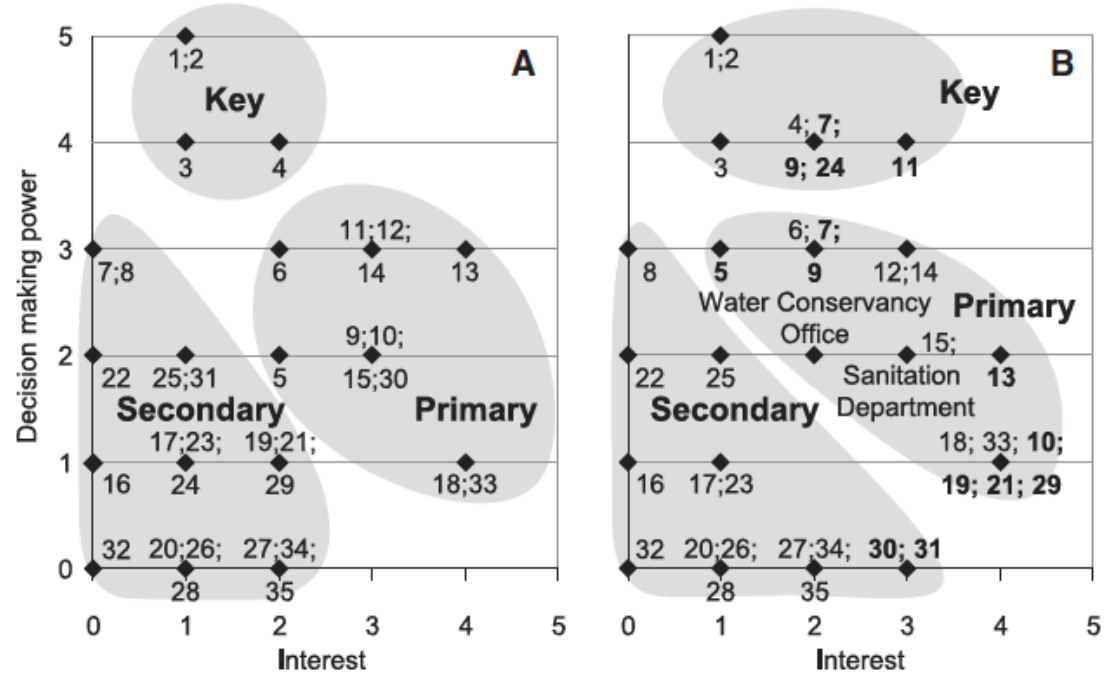

Fig. 6 Diagramatic representation of the stakeholders' decision making power versus interest in relation to the implementation of urine source separation in cities. The numbers refer to the stakeholders listed in Figure 5. The criteria for grouping are explained in the text. A Original stakeholder diagram prepared by the authors. B Improved stakeholder diagram after validation in a workshop with representatives from ten involved stakeholders. The changes recommended during the workshop are shown in bold. Large uncertainties are indicated by double entries

Fig. 7 Decision making process for the implementation of urine separating flushing toilets in urban areas. Numbers refer to the sequence of decision steps and are described in the text

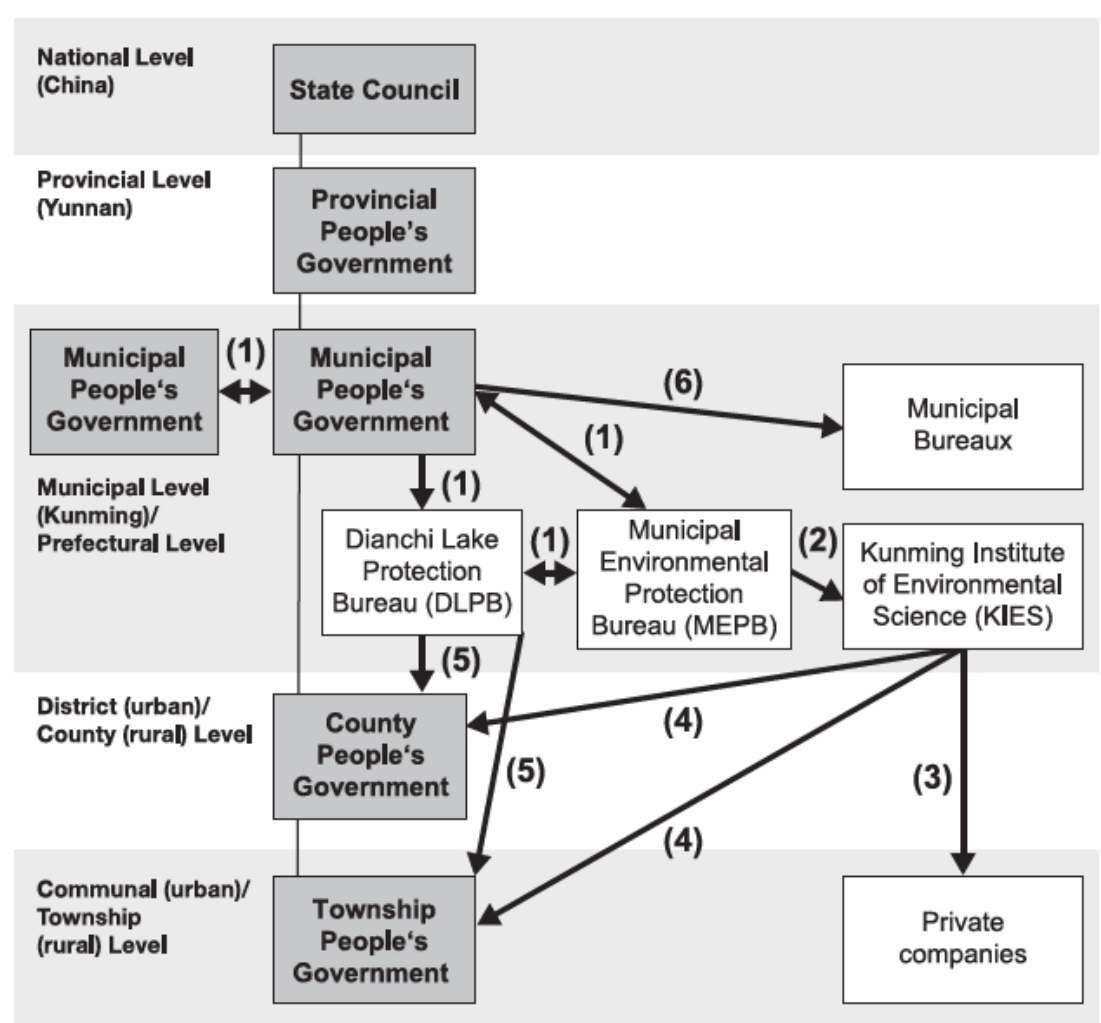

5. If the pilot project is successful and if there is a political decision to disseminate the system, DLPB will take the lead to manage this dissemination. As for the pilot project, DLPB will contract private companies directly for construction in the city of Kunming, whereas it will seek management assis- 

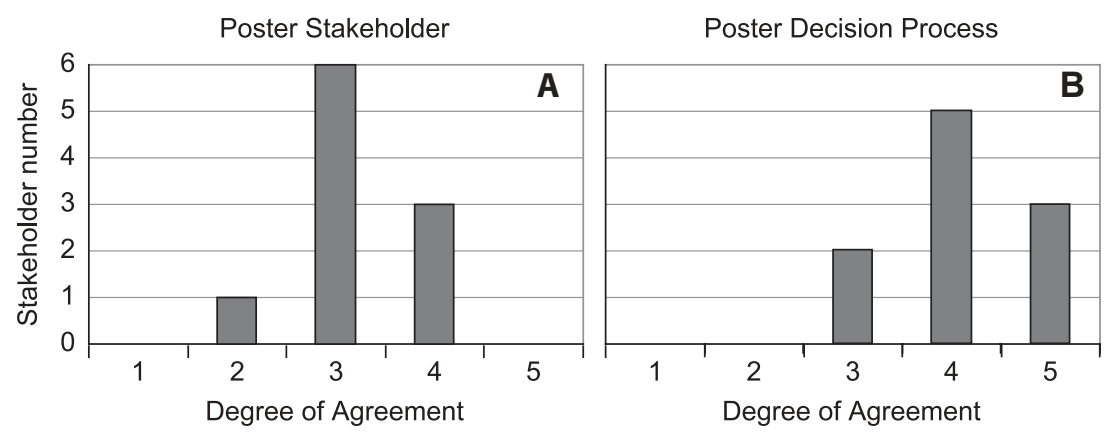

Fig. 8 Results of the evaluation by 10 stakeholder representatives: $\mathbf{A}$ the stakeholder diagram and $\mathbf{B}$ the decision making process to implement urine source separating in urban areas.

The scale of the degree of agreement stretches from "I do not agree at all"

(1) to "I fully agree" (5)

tance from local governments for smaller towns outside of Kunming.

6. Different governmental bodies will play their respective roles in the administrative and operative processes of the implementation, but not in the decision-making process. They can, however, play a decision support role when they are required to contribute with their field of expertise. These governmental bodies are active mainly at the municipal level (the city of Kunming), but they also pass information on their activities to their counterparts at the provincial level. In Figure 7, these offices, mainly the Water Supply Company within the Public Utilities Bureau, the Civil Construction Bureau, the Agricultural Bureau, the Public Health Bureau, the Urban Planning Bureau, the Sewer Corporation, and the Financial Bureau are grouped under "Municipal Bureaux."

Workshop: Feedback from Stakeholders and Adjustment of the Results

A sound and confirmed understanding of the decisionmaking process and the stakeholders is a crucial first step to understand the institutional potential and pathway to introduce urine source separation in the city. In order to receive feedback on those results, we presented them in the frame of a one-day workshop in Kunming. Representatives of ten Chinese stakeholders were present at the workshop to assess the results. The following stakeholders were present (numbers refer to Figure 5):

- Dianchi Lake Protection Bureau (\#4)

- Sewer Corporation (\#8)
- Provincial Environmental Protection Bureau (\#9)

- Provincial Environmental Research Institute (\#10)

- Municipal Environmental Protection Bureau (\#11)

- Kunming Institute of Environmental Science (\#12)

- Yunnan Academy of Social Science (\#18)

- Provincial Fertilizer Station (\#19)

- Municipal Public Health Bureau (\#21)

- Municipal Agriculture Department (\#23)

The stakeholder diagram and derived decisionmaking process mechanism (Figures 6A and 7, respectively) were evaluated by the workshop participants. The results of this evaluation are shown in Figure 8.

The acceptance of the stakeholder diagram was only average, whereas the extrapolated decisionmaking process was very well approved. The discussion that took place during the workshop allowed improvement of consensus on both posters. The recommended changes to the stakeholder diagram are presented in Figure 6B and further described in the following subsections.

\section{Group: Key stakeholders}

The positions in the diagram of the initially identified key stakeholders were well accepted. The stakeholders agreed that the Congress (\#3), Government (\#1), and Communist Party (\#2) are the final decision-makers, whereas the Dianchi Lake Protection Bureau (\#4) represents the most prominent body of experts for all issues related to Dianchi Lake protection. From the other identified stakeholders, however, some were additionally considered as key stakeholders. The Municipal Environmental Protection Bureau (MEPB \#11, municipal level) as well as the Yunnan Environmental Protection Bureau (YEPB \#9, provincial level) 
were both granted slightly more decision power than previously evaluated. For the latter, however, less interest in urine source separation was assumed because an urban project in Kunming falls directly under the responsibility of MEPB. This is also why some of the stakeholder representatives preferred to give YEPB a bit less decision power than MEPB.

Real estate companies (\#7) were reevaluated with a stronger interest and some gave them stronger decision-making power. The stakeholders present argued that real estate companies involved in the construction of houses with innovative sanitation would have better chances of being contracted and funded by international agencies and they considered ecological sanitation an effective selling argument. We did not investigate this possibly more crucial role of real estate companies further.

According to the stakeholders present, the Municipal Urban Planning Administration Bureau (\#24) was the most wrongly estimated stakeholder. This Bureau was considered a key decision-maker in the strategy related to the development of the city because their approval would be required in an early stage of such projects.

\section{Group: Primary stakeholders}

Two newly identified stakeholders were added to this group, namely, the Sanitation Department and the Water Conservancy Office. The former manages mainly public sanitation facilities in the city and the latter applies water-saving policies.

The level of decision-making power of the Municipal Public Utilities Bureau (\#5) was slightly increased by the stakeholder group. The reason stated was the fact that many important public services offices such as the Water Supply Company are under the authority of this Bureau. In the group evaluation, more stakeholders (\#10, \#19, \#21, \#29) were accorded a strong interest in the implementation of urban urine source separation (interest $=4$ ) than in our first estimation, but, at the same time, a very limited decision-making power.

\section{Group: Secondary stakeholders}

The notable change in this section is the village leaders (\#30, \#31), who were accorded absolutely no decisionmaking power by the workshop participants although they represent the end users of the toilets.

In summary, the initial acceptance of the stakeholder diagram during the workshop was average, but the recommendations for improvement increased our understanding. The only major improvement required for the representation of the decision-making process would be to add the newly identified Sanitation Department and the Water Conservancy Office to the group of governmental offices at the municipal level, supporting the implementation with their specific competency but not intervening in the decision-making process.

\section{Discussion}

Practical Implications

Although the present formal Chinese legislation does not seem to offer a particularly favorable framework for the implementation of alternative wastewater treatment management, the Five Year Plans are a suitable basis for change. Because the centralized wastewater treatment did not have the expected results, measures at the source in rural and periurban areas were included in the last Five Year Plan of Kunming, allowing for pilot projects with dry urineseparating toilets to be conducted in a village. The experience from such a pilot project showed that at least in a periurban context, even a small pilot project can be the basis of far-reaching decisions, provided that it is successful.

The political and administrative organization is extremely stratified. There are three main vertical levels (Party, Congress and Government) and six horizontal levels (from the national to the neighborhood level). In addition to the political and administrative organization, the research institutions play an active role in the implementation of innovative technologies for supplying public services like sanitation and water pollution control, as illustrated by the periurban case study (Figure 4).

Stakeholder analyses are used to generate knowledge about relevant actors, to understand their interrelationships and their influence in decisionmaking processes. In this case, we gained a good overview of the attitude of the different stakeholders toward urine source separation. KIES plays a central role in promoting the concept, probably due to its expertise and knowledge of the limitations of conventional wastewater treatment and due to its proximity to MEBP. It is obvious that this institute is also well placed for extrapolating the experience from periurban villages to the urban area itself. Because successful pilot projects seem to be the key element for the dissemination of alternative sanitation technologies, careful planning of such projects will be worthwhile. 
Another central role is played by DLBP, the key player with presumably the highest interest in urine source separation. Although there is general agreement that the initiative for an urban pilot project should be taken by MEBP and DLBP together (Figure 7), it is not clear what would trigger such an initiative. Again, KIES seems to be in a good position to take the initiative, especially in view of the success in periurban areas.

Two surprising aspects of stakeholder impact were presented in the concluding workshop. First, we did not expect such a high impact of the real estate companies as claimed by the participants. For time reasons, we could not pursue this interesting aspect. Second, we were surprised that the village leaders, representing the end users of the sanitary technology, were accorded very little influence. We hypothesize, however, that the influence of the end users and their leaders might materialize on a more informal level. Experience shows that in China end users might reject technology that does not suit their requirements.

\section{Implications for Methodology and Theory}

There are a large number of guidelines available for stakeholder analysis (see, e.g., Department for International Development 1995b; Grimble and Wellard, 1997) and for stakeholder involvement (see, e.g., Department for International Development 1995a, 1995c; World Bank 1996b). These guidelines are based mainly on the experience of different organizations in different projects. Using the appropriate guideline for an analysis, one expects to understand the balance of power, the conflicts of interest, and the complexity of the social system where one is going to run a project. However, even using these general guidelines, it is obvious that such an analysis will never be entirely objective. It will always be influenced by the perception of the person or group performing it, and no truly intersubjective reality will be created. For this reason, we chose to "mirror" our results with the stakeholders participating in the work; that is, we presented our results based on their information and asked them to discuss and comment on our perception of reality. Our detailed results show that this process actually worked and that stakeholders could agree on significant corrections, assuring that our final analysis was based on a broad stakeholder consensus. Perhaps even more important, this method assures that the stakeholders actively bring to mind the necessary decision processes and share the same picture of how to proceed. This means that we have in fact combined stakeholder analysis with stakeholder involvement, a step that is normally not performed in the established methodologies. Stakeholder analysis and stakeholder involvement are at the moment two different approaches; in our opinion, it would be crucial to connect them. Based on the results from the stakeholder analysis, one should be able to draw meaningful conclusions about stakeholder involvement. Furthermore, in the available approaches for stakeholder involvement, the step from the participative process to actual implementation is not considered. Because in our approach the stakeholders are made aware of the decision-making process and mutually confirming this knowledge, such a step follows naturally.

On the theoretical level, our study shows how important it is to consider stakeholder perceptions in addition to the existing formal legal framework, although some authors assume that primarily the latter dictates how decision processes will run (see Buchanan and Tullock 1962; Discussion in Shugart and Tollison 2005). Our results suggest that one must assume an interaction between the formal and informal framework. In the classification scheme of Lowi (1964) concerning the arenas of political relationships, this corresponds to the arena of "distribution," where the primary decision locus is described as a congress committee or agency and the implementation agency is anticipated to be centralized. On the one hand, the actors follow the formal decision pathways (e.g., the governmental bureaus and the municipal government), and on the other hand, they give the informal pathways (e.g., research institutes and real estate companies) equal weight. This is in fact rather surprising for China, where the state is very hierarchically organized and one would assume that nothing would be possible without acceptance from the highest place.

\section{Conclusion}

Because urine is the largest single source of phosphorus and nitrogen in domestic wastewater, the introduction of urine-separating toilets has a high potential to reduce the nutrient discharges to Dianchi Lake, one of the most heavily polluted lakes of national importance in China. The present legislative system in China does not explicitly support practical trials and implementation of decentralized sanitation alternatives, but there is flexibility enough to allow for pilot projects within the frame of a Five Year Plan.

In the present project, practical experience was gained in a pilot project testing the technology of dry urine-separating toilets in a periurban area. The pilot 
project was highly successful and built the basis for a hypothetical decision-making process for a similar project in the urban area of Kunming. Based on a stakeholder diagram, we concluded that although a number of primary stakeholders have a large interest in testing urine separation in an urban context, most of the key stakeholders would be reluctant to accept such an idea. However, the success in the periurban area showed that even a single, relatively small successful pilot project can trigger the process of broad dissemination of such technologies.

Methodologically, we developed an approach to corroborate a stakeholder analysis with the perception of the stakeholders themselves. This is important not only in order to validate the analysis but also to bridge the theoretical gap between stakeholder analysis and stakeholder involvement. We also showed that in disagreement with the assumption of most policy theories, local stakeholders consider informal decision pathways to be of great importance in actual policymaking.

Acknowledgments This project was financed by the Swiss Agency of Development and Cooperation (SDC) and the Swiss National Science Foundation (SNF) in the frame of the National Competence Centre, NCCR North South Programme. Within the NCCR North South Programme, the authors want to especially thank Jean Claude Bolay (Laboratoire de Sociologie Urbaine, ENAC/INTER, Swiss Federal Institute of Technology of Lausanne), Michael Kollmair and Susan Thieme (Development Study Group, Department of Geography, University of Zurich), and Isabelle Milbert, Antoine Kernen, and Patrick Botazzi [Institut universitaire d'études du développement (IUED), University of Geneva] for their contribution during the development of the research methodology.

The authors thank the Yunnan Academy of Social Sciences, the Kunming Institute of Environmental Science, the Dianchi Lake Protection Bureau, and the city of Kunming for their collaboration. Mr. Lin Jiang, from the Guangxi Committee of the Jiu San Society, Department of Science and Technology, and Ms. Li Lingling, from the Committee of Guangxi, Office of Patriotic Health Campaign, are especially thanked for their participation as experts in the implementation of urine separating dry toilets near Kunming. We thank Wang Lei for the research and processing of Chinese documents and data and Yvonne Lehnhard for redrawing the figures.

\section{References}

Buchanan JM., Tullock G (1962) The calculus of consent: Logical foundations of constitutional democracy. University of Michigan Press, Ann Arbor

Chen J ( 2000) Cited in World Bank (2001)

Chinagate (2004) Environmental protection in China. Available from http://www.chinagate.com.cn/english/1515.htm (ac cessed June 8, 2006)
Chinese Constitution (1982) Constitution of the People's Repub lic of China. Adopted December 4, 1982

Department for International Development (1995a) Technical note on enhancing stakeholder participation in aid activities. Available from http://www.euforic.org/gb/stake2.htm (ac cessed June 8, 2006)

Department for International Development (1995b) Guidance note on how to do stakeholder analysis of aid projects and programmes. Available from http://www.euforic.org/gb/sta ke1.htm (accessed June 8, 2006)

Department for International Development (1995c) Guidance note on indicators for measuring and assessing primary stakeholder participation. Available from http://www.eufor ic.org/gb/stake3.htm (accessed June 8, 2006)

Feiner J (2004) Shaxi Valley Rehabilitation Project. Available from http://www.nsl.ethz.ch:16080/irl/shaxi/frameset/frame Overview.htm (accessed June 8, 2006)

Grimble R, Wellard K (1997) Stakeholder methodologies in natural resource management: A review of principles, contexts, experiences and opportunities. Agric Syst 55(2):173 193

Huang D B, Bader H P, Scheidegger R, Schertenleib R, Gujer W (in press) Confronting limitations: New solutions required for urban water management in Kunming City. J Environ Manage. doi:10.1016/jenuman.2006.05.004

KUPDI (Kunming Urban Planning and Design Institute) (2003) Planungskonzept des Stadtesystems um den Diansee: Die "Vier Zonen um den See" Plannung. Internal document (in German)

Larsen TA, Gujer W (2001) Waste design and source control lead to flexibility in wastewater management. Water Sci Technol 43(5):309 317

Larsen TA, Peters I, Alder A, Eggen R, Maurer M, Muncke J (2001) Re engineering the toilet for sustainable wastewater management. Environ Sci Technol 35(9):192A 197A

Lienert J, Larsen TA (2006) Considering consumer attitude in early development of environmentally friendly technology: A case study of the NoMix toilets. Environ Sci Technol 40:4838 4844

Lowi T. (1964) Americal business, public policy, case studies, and political theory. World Politics 16(4):677 715

Medilanski E, Liang C, Mosler H J, Schertenleib R, Larsen TA (2006) Wastewater management in Kunming, China: Feasi bility and perspectives of source separation from a stake holder point of view. Environ Urban 18(2):353 368

Mi S. (2001) Implementing comprehensive planning in the People's Republic of China. Postgraduate paper in spatial planning (Raumplanung NDS ORL 1999/2001). Swiss Fed eral Institute of Technology Zurich

NCCR North South (2005) News, 14/03/2005. Available from http://www.nccr north south.unibe.ch/default.asp (accessed June 8, 2006)

North D (1990) Institutions, institutional change and economic performance. Cambridge University Press, New York

Schertenleib R, Morel A, Kalbermatten J, Saywell D (2003) Guidelines for the implementation of the Bellagio Princi ples and the household centred environmental sanitation approach (HCES). In Proceedings of the 2nd International Ecosan Symposium. IWA, GTZ, Lubeck, Germany, pp 93 100

Shughart WF II, Tollison RD (2005) The unfinished business of public choice. Public Choice 124:237 247

Task Group (2001) 10th Five Year Plan. Kunming. Task Group of Water Pollution Control in Dianchi Catchment Area (in Chinese) 
UNEP International Environmental Technology Centre (2002) Environmentally sound technology for wastewater and stormwater management: An international source book. IWA Publishing, London

World Bank (1996a) Environmental assessment report Draft Executive Summary. Yunnan Environmental Project Office, Yunnan Institute of Environmental Sciences in association with Montgomery Watson, GHK/MRM International, Hunting Technical Services, Severn Trent Water Interna tional, Washington DC
World Bank (1996b) The World bank participation sourcebook. Available from http://www.worldbank.org/wbi/sourcebook/ sbhome.htm (accessed June 6, 2006)

World Bank (2001) China Air, land and water: environmental priorities for a new millennium. The International Bank for Reconstruction and Development/The World Bank, Wash ington, DC

World Bank (2003) A user's guide to poverty and social impact analysis. The International Bank for Reconstruction and Development/The World Bank, Washington, DC. Available from http://www.worldbank.org/psia (accessed June 8, 2006) 